\title{
PREVALENSI RETINOPATI DIABETIK PADA PENDERITA DIABETES MELITUS DI BALAI KESEHATAN MATA MASYARAKAT (BKMM) PROPINSI SULAWESI UTARA PERIODE JANUARI - JULI 2014
}

\author{
Yellien R Manullang ${ }^{1}$, Laya Rares ${ }^{2}$, Vera Sumual ${ }^{2}$ \\ ${ }^{1}$ Kandidat Skripsi Fakultas Kedokteran Universitas Sam Ratulangi \\ ${ }^{2}$ Bagian Ilmu kesehatan Mata RSUP Prof. Dr. R. D. Kandou Manado \\ Email: yellien.m@gmail.com
}

\begin{abstract}
Abstrak: Penyakit mata merupakan kelainan pada mata yang dapat mempengaruhi penglihatan sehingga menyebabkan ketajaman penglihatan menurun dan penglihatan menjadi kabur atau dapat menyebabkan kebutaan. Salah satu penyebab paling sering kasus kebutaan yaitu retinopati diabetik. Retinopati diabetik merupakan kelainan retina (retinopati) yang ditemukan pada penderita diabetes melitus. Salah satu komplikasi dari DM adalah komplikasi mikrovaskular pada mata yaitu retinopati yang jika terus berlanjut akan menjadi penyebab kebutaan. Tujuan penelitian ini untuk mengetahui prevalensi retinopati diabetik pada penderita diabetes melitus di Balai Kesehatan Mata Masyarakat (BKMM) periode Januari - Juli 2014. Metode penelitian bersifat deskriptif retrospektif dengan memanfaatkan data sekunder berupa catatan rekam medik yang terdapat di Balai Kesehatan Mata Masyarakat (BKMM). Dalam penelitian ini didapatkan bahwa jumlah penderita pasien retinopati diabetik pada Januari - Juli 2014 sebanyak 64 orang. Jumlah penderita retinopati diabetik lebih banyak pada perempuan dengan jumlah 42 orang (66\%) sedangkan pada laki-laki hanya berjumlah 22 orang (34\%) dengan perbedaan jumlah antara perempuan dan laki-laki sebanyak 32\%. Sedangkan untuk kelompok umur didapatkan hasil jumlah pasien retinopati terbanyak adalah pada kelompok umur 45-64 tahun dengan jumlah sebanyak 43 orang (67\%). Berdasarkan tipe retinopati diabetik, diperoleh hasil presentase terbesar adalah pasien dengan PDR (Proliferatif Diabetik Retinopathy) dengan jumlah sebanyak 40 orang (62,50\%), dan dari hasil penelitian didapatkan bahwa terdapat pasien yang mengalami PDR + NPDR sebanyak 8 orang (12,50\%).
\end{abstract}

Kata Kunci : Prevalensi, retinopati diabetik, diabetes mellitus

\begin{abstract}
Eye disease is a disorder of the eye that can affect vision, causing decreased visual acuity and vision becomes blurred or can cause blindness. One of the most common causes of blindness is diabetic retinopathy.Diabetic retinopathy is a retinal disorders (retinopathy) were found in patients with diabetes mellitus. One of the complications of DM is microvascular complications in the eye, namely retinopathy which if continued would be a cause of blindness. The purpose of this study was to determine the prevalence of diabetic retinopathy in patients with diabetes mellitus in Balai Kesehatan Mata Masyarakat (BKMM) the period January - July 2014. The research method is descriptive retrospective by making use of secondary data from medical record contained in Balai Kesehatan Mata Masyarakat (BKMM). It was found that the number of patients with diabetic retinopathy patients in January - July 2014 as many as 64 people.Number of patients with diabetic retinopathy more in women with a number of 42 people (66\%), while in males numbered only 22 people (34\%) the difference between the number of women and men as much as $32 \%$.As for the age group showed the highest number of patients with retinopathy is the age group 45-64 years with a total of 43 people (67\%).Based on the type of diabetic retinopathy, the result is the largest percentage of patients with PDR (Proliferative Diabetic Retinopathy) with a total of 40 people (62.50\%), and the result showed that there are patients with NPDR PDR + 8 people $(12.50 \%)$.
\end{abstract}

Keywords: Prevalence, diabetic retinopathy, diabetic mellitus 
Penyakit mata merupakan kelainan pada mata yang dapat mempengaruhi penglihatan sehingga menyebabkan ketajaman penglihatan menurun dan penglihatan menjadi kabur atau dapat menyebabkan kebutaan. ${ }^{1}$ Salah satu penyebab paling sering kasus kebutaan yaitu retinopati diabetik. ${ }^{2}$

Retinopati diabetik merupakan kelainan retina (retinopati) yang ditemukan pada penderita diabetes melitus. ${ }^{3}$ Diabetes melitus (DM) adalah penyakit degeneratif kronik yang memiliki angka morbiditas dan mortalitas tertinggi di dunia, ${ }^{4}$ salah satu komplikasi dari DM adalah komplikasi mikrovaskular pada mata yaitu retinopati yang jika terus berlanjut akan menjadi penyebab kebutaan. ${ }^{5}$

Retinopati akibat diabetes melitus lama berupa aneurisme, melebarnya vena, perdarahan dan eksudat lemak. Penderita diabetes melitus dengan tipe 1 (insulin dependen diabetes) dan tipe 2 (non insulin dependen diabetes) mempunyia risiko untuk mendapatkan retinopati diabetik. Makin lama menderita diabetes makin bertambah risiko untuk mendapatkan retinopati. Diabetes yang diderita lebih dari 20 tahun pada tipe 1 hampir seluruhnya dan $>60 \%$ tipe 2 menderita retinopati. Retinopati diabetes merupakan penyulit penyakit diabetes yang sangat penting. Hal ini disebabkan karena insidennya yang cukup tinggi yaitu mencapai 40-50\% penderita diabetes dan prognosisnya yang kurang baik terutama bagi penglihatan. ${ }^{3}$

Di Amerika Serikat terdapat kebutaan 5.000 orang pertahun akibat retinopati diabetes, sedangkan di Inggris retinopati diabetes merupakan penyebab kebutaan nomor 4 dari seluruh penyebab kebutaan. ${ }^{3}$ Prevalensi retinopati diabetik pada pasien diabetes melitus tipe 1 setelah 10-15 tahun sejak diagnosis ditegakkan berkisar antara 25-50\%. Sesudah 15 tahun prevalensi meningkat menjadi $75-95 \%$ dan setelah 30 tahun mencapai 100\%. Pasien diabetes tipe 2 ketika diagnosis diabetes ditegakkan sekitar 20\% diantaranya telah ditemukan retinopati diabetik. Setelah 15 tahun kemudian prevalensi meningkat menjadi lebih dari 60-85\%. Di Amerika Utara dilaporkan sekitar 12.000-24.000 pasien diabetes mengalami kebutaan setiap tahun. Di Inggris dan Wales tercatat sekitar 1000 pasien diabetes setiap tahun mengalami kebutaan sebagian sampai kebutaan total. ${ }^{6}$ Berdasarkan uraian diatas retinopati diabetik merupakan salah satu masalah yang sangat penting dalam ilmu kesehatan mata, sehingga penulis tertarik melakukan penelitian untuk mengetahui seberapa banyak penderita retinopati diabetik yang berkunjung ke Balai Kesehatan Mata Masyarakat (BKMM) Propinsi Sulawesi Utara periode Januari Juli 2014 serta dapat mengetahui prevalensi dari periode tersebut.

\section{RUMUSAN MASALAH}

Dengan memperhatikan latar belakang diatas maka rumusan masalah penelitian yaitu "Bagaimana prevalensi retinopati diabetik pada penderita diabetes melitus di Balai Kesehatan Mata Masyarakat (BKMM) Propinsi Sulawesi Utara periode Januari - Juli 2014 ?” 


\section{METODE PENELITIAN}

Jenis penelitian yang dilakukan adalah bersifat deskriptif retrospektif dengan menggunakan data rekam medis penderita retinopati diabetik di Balai Kesehatan Mata Masyarakat Propinsi Sulawesi Utara periode Januari - Juli 2014. Variabel penelitian adalah penderita diabetes, jenis kelamin, rentang umur, tipe retinopati diabetik.

\section{HASIL PENELITIAN}

Penelitian dilakukan di Balai Kesehatan Mata Masyarakat dari data yang diambil dari rekam medik periode JanuariJuli 2014. Berdasarkan hasil penelitian yang dilaksanakan, pada periode Januari- Juli 2014 terdapat 64 penderita retinopati diabetik. Hal-hal yang diamati yaitu jenis kelamin, usia, diagnosis tipe retinopati diabetik.

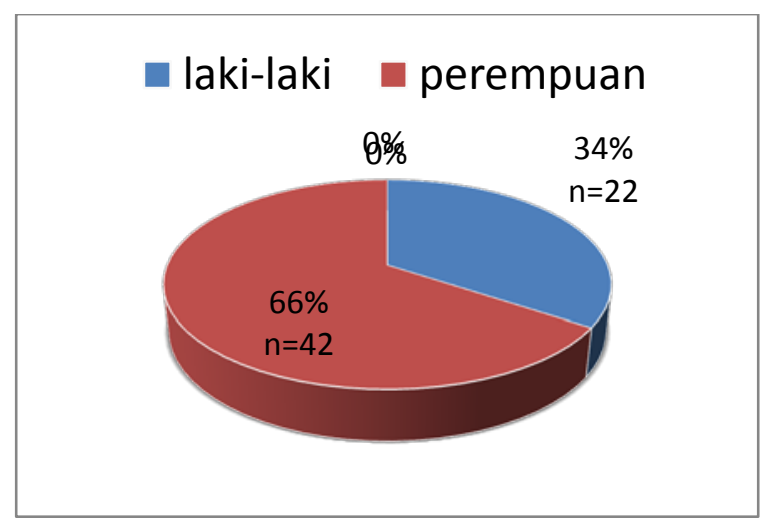

Gambar 1. Distribusi Pasien Berdasarkan Jenis Kelamin

Berdasarkan jumlah dan presentase pada gambar diatas menyatakan bahwa pasien yang berjenis kelamin perempuan lebih banyak dibandingkan dengan laki-laki. Hal ini dapat dilihat dan diketahui dari jumlah data rekam medis yang dimana data pasien yang berobat dengan diagnosis retinopati diabetik yang terbanyak adalah perempuan.

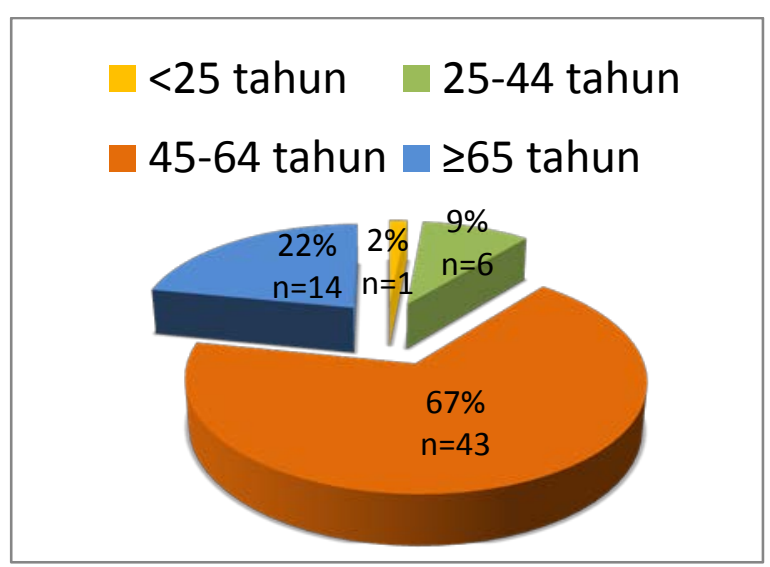

Gambar 2. Distribusi Pasien Berdasarkan Kelompok Umur

Berdasarkan gambar 2 diatas dapat diketahui dari data rekam medis yang diambil bahwa umur 45-64 tahun adalah kelompok umur yang tersering mengalami retinopati diabetik dibandingkan dengan kelompok umur lainnya (dari responden umur $<25$ tahun hingga $\geq 65$ tahun).

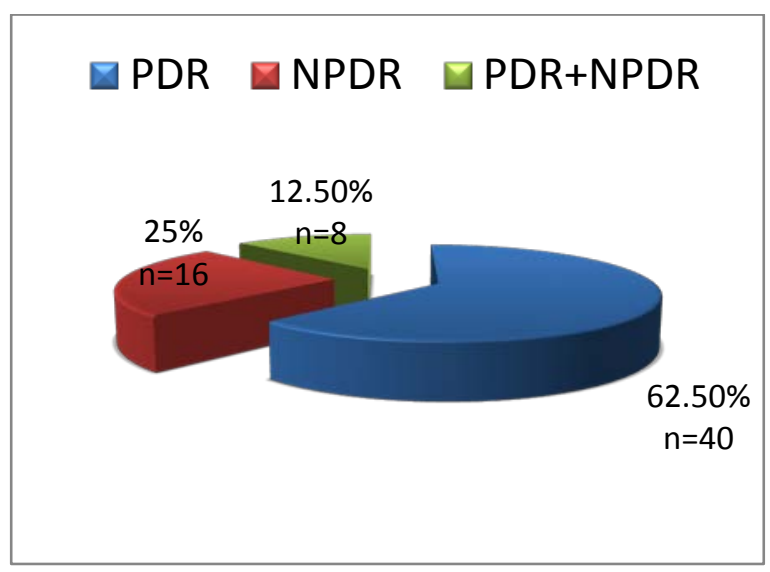

Gambar 3. Distribusi Pasien Berdasarkan Tipe Retinopati Diabetik

Berdasarkan gambar 3 dapat dilihat bahwa dari 64 orang presentase terbesar dari pasien yang mengalami penyakit retinopati 
diabetik adalah tipe retinopati diabetik proliferatif. Hal ini dikarenakan pasien yang tidak rutin mengontrol dan keterlambatan pengobatan. Dari data tersebut ternyata didapatkan juga pasien dengan kedua diagnosis yaitu PDR+NPDR namun dari data yang didapatkan hanya sedikit pasien yang mengalami diagnosis tersebut.

\section{PEMBAHASAN}

Diabetik retinopati merupakan penyulit penyakit Diabetes Melitus yang paling ditakuti, karena insidennya yang cukup tinggi dan prognosanya yang kurang baik bagi penglihatan. Retinopati diabetik adalah suatu mikroangiopati progresif yang ditandai oleh kerusakan dan sumbatan pemuluh-pembuluh halus, meliputi arteriol prekapiler retina, kapiler-kapiler dan venavena. $^{7}$

Berdasarkan hasil penelitian yang dilakukan dengan sampel pasien yang mengalami retinopati diabetik yang diambil dari laporan catatan rekam medis terdapat sebanyak 64 orang pada periode Januari Juli 2014

Hasil yang diperoleh berdasarkan jenis kelamin didapatkan bahwa pasien penderita retinopati diabetik lebih banyak pada perempuan dengan jumlah 42 orang (66\%) sedangkan pada laki-laki hanya berjumlah 22 orang (34\%) dengan perbedaan jumlah antara perempuan dan laki-laki sebanyak 32\%. Hasil penelitian ini tidak berbeda dengan hasil penelitian yang dilakukan sebelumnya oleh Tiara Ilary $(2014)^{8}$ dan Venesia Pengan (2014), ${ }^{9}$ dimana hasil penelitian yang didapatkan pasien yang berjenis kelamin perempuan lebih banyak terkena retinopati diabetik diabandingkan dengan pasien laki-laki. Pernah dikatakan bahwa hormon estrogen berpengaruh pada DM, dimana wanita DM memiliki kecenderungan retinopati lebih tinggi daripada pria. Tingginya angka retinopati pada wanita dikaitkan dengan tingginya angka kegemukan pada wanita terkait genetik dan pola hidup yang merupakan faktor resiko DM. Hormon estrogen merupakan hormon seks dominan pada wanita, kadar hormon estrogen yang tinggi dapat menurunkan leptin yang berperan dalam penekan napsu makan di hipotalamus, akibatnya asupan makanan tidak terkontrol, sehingga dapat menyebabkan penumpukan jaringan lemak berlebih disertai tingginya kadar gula darah akibat terjadinya penurunan sensitifitas jaringan perifer terhadap insulin. ${ }^{10,3}$ Namun terdapat perbedaan dengan hasil penelitian yang dilakukan oleh Juniar Anugrah (2013), ${ }^{11}$ dimana didapatkan pasien laki-laki memiliki sebaran lebih banyak dibandingkan dengan perempuan. Tetapi data ini tidak dapat menjelaskan hubungan antara retinopati diabetik dengan jenis kelamin dikarenakan ketidaksesuain antara teori dan hasil penelitian ini kemungkinan dipengaruhi oleh kurang representatifnya jumlah sampel yang diambil.

Berdasarkan kelompok umur (rentang usia) didapatkan hasil jumlah pasien retinopati terbanyak adalah pada kelompok umur 45-64 tahun dengan jumlah sebanyak 43 orang (67\%). Hasil ini tidak berbeda dengan hasil penelitian dari Tiara Ilary $(2014)^{8}$ dimana pasien terbanyak adalah pada rentang usia 45-64 tahun. Tetapi berbeda dengan hasil penelitian dari Juniar 
Anugrah (2013) ${ }^{11}$ didapatkan jumlah terbanyak pasien retinopati diabetik pada usia 60-69 tahun sebanyak 33,33\%. Dari beberapa teori yang ada retinopati diabetik terjadi karena lamanya memiliki riwayat diabetes melitus. Terkait dengan usia 45-64 tahun yang lebih banyak mengalami retinopati diabetik dikarenakan semakin meningkatnya umur maka intoleransi terhadap glukosa juga meningkat sehingga orang dengan riwayat diabetes melitus yang lama pada usia $>45$ lebih banyak mengalami retinopati diabetik. Didukung juga dari beberapa teori yang ada bahwa pada usia $>40$ tahun metabolisme dan struktur-struktur selnya lebih susah beradaptasi dan bekerja lebih lambat.

Berdasarkan tipe retinoopati diabetik, diperoleh hasil bahwa presentase terbesar yang dialami pasien retinopati diabetik menurut klasifikasinya adalah pasien dengan PDR (Proliferatif Diabetik Retinopathy) dengan jumlah sebanyak 40 orang $(62,50 \%)$, dan dari hasil penelitian didapatkan bahwa terdapat pasien dengan deiagnosis keduanya yaitu PDR + NPDR sebanyak 8 orang $(12,50 \%)$. Belum diketahui faktor apa saja yang menyebabkan peningkatan PDR lebih banyak di bandingkan NPDR, sehingga perlu dilakukan penelitian lebih lanjut agar bisa membuktikan faktor apa saja yang membuat peningkatan PDR lebih banyak dibandingkan NPDR.

\section{KESIMPULAN}

Hasil penelitian pada pasien retinopati diabetik di Balai Kesehatan Mata
Masyarakat dapat diambil kesimpulan bahwa:

1. Terdapat pasien retinopati diabetik yang berjenis kelamin perempuan lebih banyak daripada pasien yang berjenis kelamin laki-laki dengan presentase peningkatan pada jenis kelamin perempuan lebih tinggi yaitu sebesar $66 \%$.

2. PDR (Proliferatif Diabetik Retinopathy) merupakan tipe retinopati diabetik yang paling banyak ditemukan dibandingkan dengan tipe yang lainnya dengan jumlah presentase $62,50 \%$ (40 orang).

3. Ditemukan kelompok umur terbanyak yang mengalami retinopati diabetik adalah 45-64 tahun dengan jumlah 43 orang (67\%).

\section{SARAN}

Diharapkan kepada penderita retinopati diabetik untuk rutin mengontrol kadar gula darah, tekanan darah serta rutin untuk memeriksakan mata, dan dianjurkan agar dapat segera melakukan penanganan untuk meminimalisir adanya resiko kebutaan serta komplikasi lainnya. Diharapkan kepada penderita juga untuk mengontrol asupan makanan dan kebutuhan kalori yang diperlukan disertai dengan berolahraga secara teratur. Selain itu perlu untuk mengontrol kadar kolestrol agar dapat mencegah komplikasi lebih dini. Untuk pasien dengan adanya riwayat Diabetes Melitus agar segera berobat dan rutin mengontrol sehingga dapat mencegah terjadinya retinopati diabetik. Diperlukan penelitian lebih lanjut dengan sampel yang lebih besar untuk mengetahui prevalensi penderita retinopati diabetik serta agar dapat 
mengetahui hubungan retinopati diabetik dengan faktor resiko lainnya.

\section{DAFTAR PUSTAKA}

1. Suhendar A, Nuryadhin S, Saefudin. Sistem identifikasi gangguan mata dengan menggunakan pendekatan rule based system. Prosiding SNaPP Sains, Teknologi, dan Kesehatan. 2014;4:237-44.

2. Fong DS, Aiello L, Gardner TW, King GL, Blankenship G, Cavallerano JD, et.al. Diabetic Retinopathy. American Diabetes Association. [cited 2015 Oct 03]. Available from:

http://care.diabetesjournals.org/con tent/26/suppl_1/s99.full

3. Ilyas HS, Yulianti SR. Ilmu penyakit mata. Edisi ke-5. Jakarta: Fakultas Kedokteran Universitas Indonesia; 2014.

4. Sitompul R. Retinopati diabetik. J Indon Med Assoc. 2011;61:337-41.

5. Noble J, Chaudhary V. Diabetic retinopathy. CMAJ. 2010; 182(15):1646.

6. Pandelaki K. Diabetes melitus. Retinopati Diabetik. In: Setiati S, Alwi I, Sudoyo AW, K Marcellus Simadibrata, Setiyohadi B, Syam AF. Ilmu penyakit dalam. Edisi ke6. Jakarta: Interna Publishing; 2014. p. 2400-406.

7. Lubis RR. Diabetik retinopati. Medan: FK USU; 2007. h. 2-11.

8. Ilary T. Prevalensi retinopati diabetik pada poliklinik ilmu kesehatan mata selang satu tahun. E-Clinic. 2014
9. Pengan V. Kecenderungan penderita retinopati diabetik. E-Clinic. 2014:2

10. P. Gæde., 2003, “Multifactorial intervention and cardiovascular disease in patients with type 2 diabetes," New England Journal of Medicine., 348(5):383-393.

11. Anugrah J. Hubungan diabetes melitus dan retinopati di RSUD DR Soedorso Pontianak periode Januari- Desember 2010. FK Universitas Tanjungpura; 2013. 